University of Wollongong

Research Online

Faculty of Engineering and Information

Faculty of Engineering and Information

Sciences - Papers: Part A

Sciences

$1-1-2014$

\title{
An approach for assessing the effectiveness of multiple-feature-based SVM method for islanding detection of distributed generation
}

Mollah R. Alam

University of Wollongong, mra497@uowmail.edu.au

Kashem M. Muttaqi

University of Wollongong, kashem@uow.edu.au

Abdesselam Bouzerdoum

University of Wollongong, bouzer@uow.edu.au

Follow this and additional works at: https://ro.uow.edu.au/eispapers

Part of the Engineering Commons, and the Science and Technology Studies Commons

Research Online is the open access institutional repository for the University of Wollongong. For further information contact the UOW Library: research-pubs@uow.edu.au 


\title{
An approach for assessing the effectiveness of multiple-feature-based SVM method for islanding detection of distributed generation
}

\author{
Abstract \\ Islanding detection is a critical protection issue, as conventional protection schemes such as vector \\ surge (VS) and rate of change of frequency relays do not guarantee islanding detection for all network \\ conditions. Integration of multiple distributed generation (DG) units of different sizes and technologies \\ into distribution grids makes this issue even more critical. This paper presents a comprehensive analysis \\ of the effectiveness of a new method for islanding detection in DG networks. The proposed method, \\ which is based on multiple features and support vector machine (SVM) classification, has the potential to \\ overcome the limitations of conventional protection schemes. The multifeature-based SVM technique \\ utilizes a set of features generated from numerous set of offline dynamic events simulated under \\ different network contingencies, operating conditions, and power imbalance levels. Parameters (such as \\ voltage, frequency, and rotor angle) showing distinguishable variation during the formation of islanding \\ are selected as features for classification of the events. Features associated with different islanding and \\ nonislanding events are used to train the SVM. The trained SVM is tested on a typical distribution network \\ containing multiple DG units. Simulation results indicate that the proposed method can work effectively \\ with high degree of accuracy under different network contingencies and critical levels of power imbalance \\ that may exist during islanding.

\section{Keywords} \\ effectiveness, multiple, feature, svm, approach, method, assessing, islanding, detection, distributed, \\ generation

\section{Disciplines} \\ Engineering | Science and Technology Studies

\section{Publication Details} \\ M. Rezaul. Alam, K. M. Muttaqi \& A. Bouzerdoum, "An approach for assessing the effectiveness of \\ multiple-feature-based SVM method for islanding detection of distributed generation," IEEE Transactions \\ on Industry Applications, vol. 50, (4) pp. 2844-2852, 2014.
}




\section{An Approach for Assessing the Effectiveness of Multiple-Feature-Based SVM Method for Islanding Detection of Distributed Generation}

\author{
M. R. Alam \\ Student Member, IEEE \\ School of Electrical, Computer and \\ Telecommunications Engineering \\ University of Wollongong \\ NSW 2500, Australia \\ mra497@uowmail.edu.au
}

\author{
K. M. Muttaqi \\ Senior Member, IEEE \\ School of Electrical, Computer and \\ Telecommunications Engineering \\ University of Wollongong \\ NSW 2500, Australia \\ kashem@uow.edu.au
}

\author{
A. Bouzerdoum \\ Senior Member, IEEE \\ School of Electrical, Computer and \\ Telecommunications Engineering \\ University of Wollongong \\ NSW 2500, Australia \\ bouzer@uow.edu.au
}

\begin{abstract}
Islanding detection is a critical protection issue, as conventional protection schemes such as vector surge (VS) and rate of change of frequency (ROCOF) relays do not guarantee islanding detection for all network conditions. Integration of multiple distributed generation (DG) units of different sizes and technologies into distribution grids makes this issue even more critical. This paper presents a comprehensive analysis of the effectiveness of a new method for islanding detection in DG networks. The proposed method, which is based on multiple features and support vector machine (SVM) classification, has the potential to overcome the limitations of conventional protection schemes. The multifeature-based SVM technique utilizes a set of features generated from numerous set of offline dynamic events simulated under different network contingencies, operating conditions and power imbalance levels. Parameters (such as voltage, frequency and rotor angle) showing distinguishable variation during the formation of islanding are selected as features for classification of the events. Features associated with different islanding and non-islanding events are used to train the SVM. The trained SVM is tested on a typical distribution network containing multiple DG units. Simulation results indicate that the proposed method can work effectively with high degree of accuracy under different network contingencies and critical levels of power imbalance that may exist during islanding.
\end{abstract}

Index Terms--Distributed generation, distribution systems, islanding detection, power imbalance, support vector machine.

\section{INTRODUCTION}

Power generation at distribution level using distributed generation (DG) has gained widespread attention due to its ability to improve reliability and security of distribution systems. However, DG energized distribution networks can give rise to a number of problems when it is disconnected unintentionally from the power grids due to large disturbances. This can introduce power quality, safety and operational problems [2]. When the mains supply fails, a distribution network with DG can become isolated from the mains and form an island. In order to avoid this hazardous condition, the DG system has to be disconnected (or switched off) as soon as islanding occurs; according to IEEE 15472003, the disconnection time should be less than 2 seconds.

A special protection system known as islanding detection relay is used to detect islanding. Normally, this relay is operated by different methods such as active, passive, or communication based methods [3]. Passive methods have low cost but it display poor performance when power imbalance in the islanded network is very small, resulting to a large non-detection zone [1]. However, with the introduction of intelligent based approaches, passive islanding detection has gained special interest over the past few years, considering cost, accuracy, computational time and reliability. Several papers on intelligent based approach have already been published in recent years [2-7].

This paper presents a passive islanding detection method using a multiple-feature-based SVM classification technique. The proposed method uses five features extracted from five network parameters: frequency, voltage, rotor angle, rate-ofchange-of-voltage and rate-of-change-of-frequency at DG connection point. The effectiveness of the proposed method is tested with a large number of credible islanding and nonislanding events. The method is further scrutinized by carrying out training and testing with the data extracted at different monitoring systems, with changes in network topology and also with critical islanding cases. Test results are presented for cases where traditional relays fail to detect islanding.

The remainder of the paper is organized as follows. Section II presents the behavior of network parameters under islanding situation. Section III describes the extraction of features, theory of SVM and proposed methodology to detect islanding. Generation of different islanding and nonislanding events on a test network are given in section IV. Analysis of simulated features and performance of the proposed method with the change of network topology are presented in section V. Section VI concludes the paper.

\section{Characterization OF NeTwORK PARAMETERS DURING ISLANDING}

Fig. 1 shows the single line diagram of a simple distribution network energized with a synchronous generator (SG) based DG. Opening of circuit breaker (CB) due to disturbance in power grid side results in islanding and eventually SG becomes the only source to feed the load locally. Hence, dynamic behavior of DG influences the 
change of network parameters such as voltage $(V)$, rate-ofchange-of-voltage $(d V / d t)$, frequency $(f)$, rate-of-change-offrequency $(d f / d t)$ and rotor angle $(\delta)$.

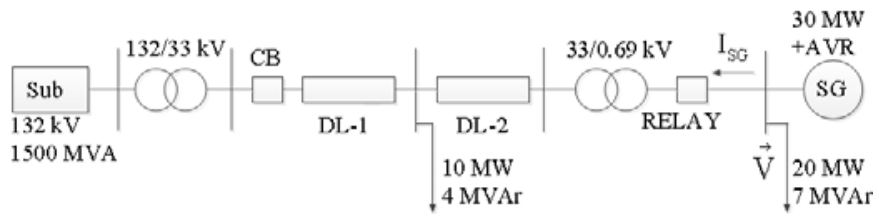

Fig. 1. Single line diagram of a simple distribution system [8]

Mathematical formulations are carried out to show the behavior of five parameters under islanding condition. The dynamic behavior of the synchronous generator can be determined by using the machine swing equation as presented below [8]:

$$
\frac{2 H}{\omega_{0}} \frac{d^{2} \delta}{d t^{2}}=\Delta P
$$

where $\mathrm{H}$ is the generator inertia constant, $\omega_{0}$ is the synchronous speed, and $\delta$ is the rotor angle with respect to synchronously rotating reference frame. Assuming the network is operating at steady-state prior to islanding $(d \delta / d t=$ 0 ), integrating (1) yields

$$
\delta(t)=\delta_{0}+\frac{\omega_{0} \Delta P t^{2}}{4 H}
$$

where $\delta_{0}$ is the rotor angle at steady state prior to islanding. The rotor angle $\delta$ is measured with respect to synchronously rotating reference frame and it varies with time during the transient period of islanding. The variation of the rotor angle during the transient is given by

$$
\frac{d \delta}{d t}=\frac{\Delta P \omega_{0} t}{2 H}
$$

The rotor speed $\omega_{r}$ can be represented as

$$
\omega_{r}=\omega_{0}+\frac{d \delta}{d t}
$$

From (3) and (4), the rotor frequency can be expressed as

$$
f_{r}=f_{0}+\frac{\Delta P f_{0} t}{2 H}
$$

Therefore, the rate-of-change-of-frequency is

$$
\frac{d f_{r}}{d t}=\frac{\Delta P f_{0}}{2 H}
$$

According to [9], islanding condition with reactive power imbalance is analogous to an incident when a pure reactive load is applied to the generator operating under no-load condition for which the voltage behavior can be presented as:

$$
V_{t}=X_{e} \cdot V \cdot\left[\frac{1}{|Z|}+\left(\frac{1}{\left|Z^{\prime}\right|}-\frac{1}{|Z|}\right) e^{-\frac{t}{\tau_{0}}}+\left(\frac{1}{\left|Z^{\prime \prime}\right|}-\frac{1}{\left|Z^{\prime}\right|}\right) e^{-\frac{t}{\tau_{1}}}\right]
$$

where $X_{e}$ is the reactive load, $V_{t}$ is the generator terminal voltage in pu. In (7), direct axis transient and subtransient time constant have been presented as $\tau_{0}$ and $\tau_{l}$ respectively. And direct axis synchronous, transient, subtransient reactances have been presented as $(|Z|),\left(\left|Z^{\prime}\right|\right)$, and $\left(\left|Z^{\prime \prime}\right|\right)$ respectively. Time domain analysis for 1 second duration is carried out where islanding occurs at 0.5 second. For this event, the terminal voltage, $V_{t}$ can be rewritten in the following form:

$V_{t}=\left\{X_{e} \cdot V \cdot\left[\frac{1}{|Z|}+\left(\frac{1}{|Z|}-\frac{1}{|Z|}\right) e^{-\frac{(t-0.5)}{\tau_{0}}}+\left(\frac{1}{\left|Z^{\prime \prime}\right|}-\frac{1}{\left|Z^{\prime}\right|}\right) e^{-\frac{(t-0.5)}{\tau_{1}}}\right] \begin{array}{l}0<t \leq 0.5 \\ 0.5<t \leq 1\end{array}\right.$

From (8), rate-of-change-of-voltage $(d V / d t)$ can be obtained as below:

$\frac{d V_{t}}{d t}=\left\{X_{e} \cdot V \cdot\left[-\frac{1}{\tau_{0}}\left(\frac{1}{\left|Z^{\prime}\right|}-\frac{1}{|Z|}\right) e^{-\frac{(t-0.5)}{\tau_{0}}}-\frac{1}{\tau_{1}}\left(\frac{1}{\left|Z^{\prime \prime}\right|}-\frac{1}{\left|Z^{\prime}\right|} e^{-\frac{(t-0.5)}{\tau_{1}}}\right]^{0<t \leq 0.5} 0.5<t \leq 1\right.\right.$

Formulation of five parameters such as $\delta, f, d f / d t, V$ and $d V / d t$ are presented in equations (2), (5), (6), (8) and (9) respectively. Response characteristic of these five parameters is carried out by simulating the network of Fig. 1 in SIMULINK. Under islanding situation, behavior of five parameters (using network simulation and theoretical formula) is presented in Fig. 2, considering a deficit of active power imbalance of $50 \%$ between load and generation within islanded network.
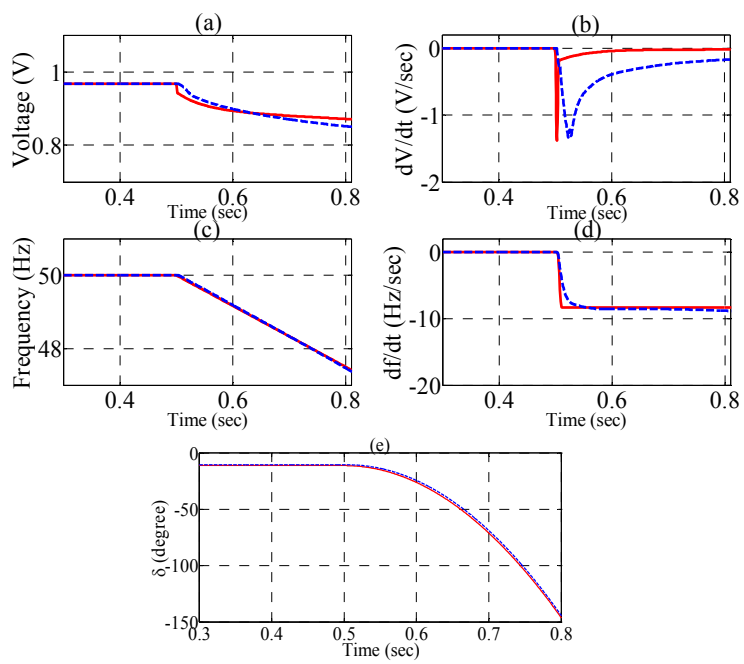

Fig. 2. Behavior of five parameters: (a) $V$, (b) $d V / d t$, (c) $f$, (d) $d f / d t$, and (e) $\delta$ under islanding condition (event inception at 0.5 second) using theoretical formula (solid line) and simulation (dash line). 


\section{MultiPle-FeAture-BASED SVM METHOD}

\section{A. Feature Extraction}

The proposed method is developed on the basis of classification of network features associated with different credible events (islanding and non-islanding). As discussed in section II, five parameters show significant variation during the transient of islanding. Therefore, in the proposed method, five features are extracted from five parameters. As presented in [2], several features are extracted by taking the average value of 8 cycles of different network variables such as voltage, frequency etc. Similarly, in this paper, standard deviation of 10 cycles of each of the five network parameters such as voltage, frequency, rate-of-change-of-frequency, rate-of-change-of-voltage, and rotor angle have been considered to extract the features needed for classification. In other words, a typical window width of 10 cycles of observation period has been considered to extract the features. Effect of window width on the features, has also been analyzed by varying the window width from 3 cycles to 10 cycles considering the similar approach as presented in [14]. Moreover, in time scale, 10 cycles represent 0.2 second for $50 \mathrm{~Hz}$ and 0.167 second for $60 \mathrm{~Hz}$ power system frequency. And, for the proposed method, this time-delay is required to trigger the islanding events. However, this timedelay is short enough in comparison to the IEEE 1547-2003 standard which states that DG should be disconnected within 2 seconds of inception of islanding. Therefore, 10 cycles of observation period is typically selected for this study. The features are presented in Table I.

TABLE I

EXTRACTED FEATURES USED FOR CLASSIFICATION

\begin{tabular}{|c|l|}
\hline Features & \multicolumn{1}{|c|}{ Description of features } \\
\hline$x_{v}$ & Standard deviation of normalized $V$ (voltage) \\
\hline$x_{f}$ & Standard deviation of normalized $f$ (frequency) \\
\hline$x_{\delta}$ & Standard deviation of normalized $\delta$ (rotor angle) \\
\hline$x_{\rho v}$ & Standard deviation of $d V / d t$ (rate-of-change-of-voltage) \\
\hline$x_{\rho f}$ & Standard deviation of $d f / d t$ (rate-of-change-of-frequency) \\
\hline
\end{tabular}

\section{B. SVM Classifier}

Support vector machines (SVMs), introduced by Vapnik and co-workers [10], are arguably one of the most successful classification methods. They have been employed in different applications for classification, feature extraction, clustering, and regression.

Our present analysis is based on binary classification of islanding and non-islanding data using SVMs. This method builds a hyperplane for separation of data into two classes in a high-dimensional feature space. A class decision function associated with a hyperplane is the weighted sum of training data set and bias,

$$
y(\boldsymbol{x})=\boldsymbol{w}^{T} \phi\left(\boldsymbol{x}_{n}\right)+b
$$

where $w$ represents the weight vector normal to hyperplane, ' $b$ ' is the bias and $x_{n}$ represents a real valued $d$ dimensional feature vector $\left(x_{n} \in \mathfrak{R}^{d}\right)$. According to the classification of SVM, new test data is assigned to a class, islanding or nonislanding, by the sign of decision function as presented below: Testing data belongs to class-1(non-islanding class) if

$$
\boldsymbol{w}^{T} \phi\left(\boldsymbol{x}_{n}\right)+b \geq 1
$$

Test data belongs to class-2(islanding class) if

$$
\boldsymbol{w}^{T} \phi\left(\boldsymbol{x}_{n}\right)+b \leq-1 \text { or, } \boldsymbol{w}^{T} \phi\left(\boldsymbol{x}_{n}\right)+b=0
$$

For linearly separable input data, SVM finds the hyperplane with the maximum Euclidean distance to the closest training samples, whereas for non-separable training sets, the amount of training error is measured by introducing a slack variable $\xi$. Mathematically, to achieve such hyperplane, $\boldsymbol{w}$ and $b$ of (10) are needed to be derived in such a way that unseen data is classified correctly and the margin of separation between the two classes is maximized as well. This whole problem can be presented as a quadratic programming (QP) optimization problem [11]:

minimize

$$
\frac{\|\boldsymbol{w}\|^{2}}{2}+C \sum_{n=1}^{N} \xi_{n}
$$

subject to the constraints

$$
y_{n}\left(\boldsymbol{w}^{T} \phi\left(\boldsymbol{x}_{n}\right)+b\right) \geq 1-\xi_{n} \quad \text { for } n=1,2, \ldots . . N
$$

where $\xi_{n}$ is measuring the distance between the margin and the samples lying on the wrong side of the margin. The parameter $C$ in (11) is a regularization parameter; it sets the relative importance of $\xi_{n}$ versus $1^{\text {st }}$ term of (11). Lagrange multipliers $\alpha_{n} \geq 0$ and $\beta_{n} \geq 0$ are introduced to solve the constrained QP problem presented in (11) and (12). The Lagrange functional can be expressed as:

$L(w, b, \xi, \alpha, \beta)$

$=\frac{1}{2}\|\boldsymbol{w}\|^{2}+C \sum_{n=1}^{N} \xi_{n}-\sum_{n=1}^{N} \alpha_{n}\left\{y_{n}\left(\boldsymbol{w}^{T} \phi\left(\boldsymbol{x}_{n}\right)+b\right)-1+\xi_{n}\right\}-\sum_{n=1}^{N} \beta_{n} \xi_{n}$

The minimization problem of (13) can be solved by introducing the dual formulation:

maximize

$$
L(\alpha)=\sum_{n=1}^{N} \alpha_{n}-\frac{1}{2} \sum_{n=1}^{N} \sum_{m=1}^{N} \alpha_{n} \alpha_{m} y_{n} y_{m} \boldsymbol{x}_{n}^{T} \boldsymbol{x}_{m}
$$

subject to the constraints

$$
\sum_{n=1}^{N} \alpha_{n} y_{n}=0 \text { and } C \geq \alpha_{n} \geq 0 \text { for } n=1,2, \ldots . N
$$

The solution of the dual problem of (14) and (15) yields $w$ of the form: 


$$
\boldsymbol{w}=\sum_{n=1}^{N} \alpha_{n} y_{n} \boldsymbol{x}_{n}
$$

The number of variables in (14) and (15) are equal to the number of training data and the vector $\boldsymbol{w}$ has an expansion in terms of a subset of the training data where the Lagrange multipliers $\alpha_{n}$ are non-zero. Those training data will also satisfy the Karush-Kuhn-Tucker (KKT) condition

$$
\alpha_{n}\left\{y_{n}\left(\boldsymbol{w}^{T} \boldsymbol{x}_{n}+b\right)-1+\xi_{n}\right\}=0 \text { for } n=1,2, \ldots . N
$$

According to (17), the training vectors corresponding to non-zero Lagrange multipliers are needed to describe the hyperplane. These training vectors are referred to as Support Vectors (SVs). The decision function $y(\boldsymbol{x})$ is determined by only using SVs and the other training data are not considered since those represent the interior points which are farther away from hyperplane in comparison to SVs. Thus, the final decision function can be given by

$$
y(\boldsymbol{x})=\sum_{\alpha_{n}>0} \alpha_{n} y_{n} \boldsymbol{x}_{n}^{T} \boldsymbol{x}+b
$$

where $\boldsymbol{x}$ is the input test vector, $\boldsymbol{x}_{n}^{T} \boldsymbol{x}$ is the inner product of data points, $b$ is the bias term and the condition $\alpha_{n}>0$ allows only the SVs of the data set.

SVMs can also perform nonlinear classification tasks. To do this, a mapping function is introduced to translate a $d$ dimensional data vector into an $m$-dimensional feature space $(m>d)$. This mapping function or kernel function provides a hyperplane which separate the classes in high dimensional feature space. In dual formulation of quadratic optimization problem, instead of using dot product of training data points in high dimensional feature space, the kernel trick is used. The kernel function defines the inner product of training data points in high dimensional feature space,

$$
k\left(\boldsymbol{x}_{i}, \boldsymbol{x}_{j}\right)=\phi^{T}\left(\boldsymbol{x}_{i}\right) \phi^{T}\left(\boldsymbol{x}_{j}\right)
$$

In this paper, the common kernel functions such as linear and polynomial kernels are used and these are defined as follows:

$$
\begin{aligned}
& k\left(\boldsymbol{x}_{i}, \boldsymbol{x}_{j}\right)=\boldsymbol{x}_{i} \boldsymbol{x}_{j} \text { (Linear kernel function) } \\
& k\left(\boldsymbol{x}_{i}, \boldsymbol{x}_{j}\right)=\left(\boldsymbol{x}_{i} \boldsymbol{x}_{j}+1\right)^{p} \\
& \text { For } p \geq 2 \quad \text { (Polynomial kernel function) }
\end{aligned}
$$

The new classification function using kernel function is defined as follows:

$$
y(\boldsymbol{x})=\sum_{\text {SVs or } \alpha_{i}>0} \alpha_{i} y_{i} k\left(\boldsymbol{x}_{i}, \boldsymbol{x}_{j}\right)+b
$$

The testing data points are classified with these binary class trained model. The performance of model is assessed using the detection rate (DR) related to islanding detection and false alarm (FA) related to nuisance tripping [17]:

$$
D R=T P /(T P+F N) \text { and } F A=F P /(F P+T N)
$$

where $T P=$ True Positive, $T N=$ True Negative, $F P=$ False Positive and $F N=$ False Negative.

DR and FA are typically used to show the performance of classifiers while dealing with classification problems. In this study, the binary classification problems, which include islanding class and non-islanding class, are encountered. DR indicates the ratio of successfully detected islanding events to the total number of islanding events whereas FA indicates the ratio of misclassification of non-islanding events to the total number of non-islanding events. In other words, DR indicates the accuracy of the proposed approach in islanding detection whereas FA specifies the rate of nuisance tripping of DG during non-islanding conditions.

\section{Proposed Methodology}

The proposed method can be described in two stages. The first stage involves the training of Support Vector Machine (SVM) with different features obtained under several islanding and non-islanding situations. In the second stage, the trained SVM is applied to detect islanding in real-time.

- Training of SVM:

The training process is summarized as follows:

1) 10 cycles of voltage $(\mathrm{V})$, frequency $(f)$ and rotor angle $(\delta)$ are extracted at the target DG location, right after inception of events (islanding and nonislanding).

2) 5 features are obtained by following the process presented in sub-section A of section III. These features are kept in a feature matrix as mentioned below:

$$
\begin{gathered}
F(n)=\left[\begin{array}{lllll}
\boldsymbol{x}_{1} & \boldsymbol{x}_{2} & \boldsymbol{x}_{3} & \ldots \ldots & \boldsymbol{x}_{n}
\end{array}\right]^{T}= \\
{\left[\begin{array}{lllll}
x_{v}(1) & x_{f}(1) & x_{\delta}(1) & x_{\rho v}(1) & x_{\rho f}(1) \\
x_{v}(2) & x_{f}(2) & x_{\delta}(2) & x_{\rho v}(2) & x_{\rho f}(2) \\
x_{v}(3) & x_{f}(3) & x_{\delta}(3) & x_{\rho v}(3) & x_{\rho f}(3) \\
\ldots \ldots & \ldots \ldots & \ldots \ldots . . & \ldots \ldots . . & \ldots \ldots . . \\
x_{v}(n) & x_{f}(n) & x_{\delta}(n) & x_{\rho v}(n) & x_{\rho f}(n)
\end{array}\right]}
\end{gathered}
$$

3) Each training sample $x_{n}$ corresponds to 5 features describing a particular signature which belongs to one of two classes i.e. $y_{n}=-1$ for islanding or $y_{n}=$ +1 for non-islanding.

4) Equation (20) is considered as the decision boundary hyperplane. Applying supervised learning algorithm, 3-fold cross-validation and grid search are carried out to obtain the optimum value of $\mathrm{C}$ and $p$ (for polynomial kernel). And with the optimum kernel parameters, SVM is trained. Then, the trained SVM is applied for testing in real-time.

- Islanding detection in real-time with trained SVM: The detection process is summarized below. 
1) Voltage $(V)$, frequency $(f)$ and rotor angle $(\delta)$ are extracted in real-time at the target DG location.

2) 5 features such as standard deviation of $V, f, \delta, d V / d t$ and $d f / d t$ are extracted in real-time within a window length of 10 cycles.

3) Feature vector $\boldsymbol{X}(i)$ is formed as below:

$$
\boldsymbol{X}(i)=\left\{x_{v}, x_{f}, x_{\delta}, x_{\rho v}, x_{\rho f}\right\}
$$

where $i$ represents the position of starting point of observation period of 10 cycles,

4) $\boldsymbol{X}(i)$ is classified with trained SVM and result is obtained as $Y(i)=-1$ for islanding or $Y(i)=+1$ for non-islanding.

5) If $Y(i)=-1$, then islanding is detected, and trip signal is sent; if $Y(i)=+1$ then step (1) to step (5) are repeated from the next cycle by increasing $i$ by 1 i.e. $i=i+1$.

The step by step procedure of real-time islanding detection is shown in the flowchart presented in Fig. 3.

Fig. 3 shows the detailed procedure of islanding detection on real-time with trained SVM. However, in this study, the applicability of the proposed method is examined by the classification results of the trained SVM with numerous offline dynamic events (islanding and non-islanding). Therefore, in the remaining sections, a test network is simulated to generate a large set of credible events and the results of classification are explored.

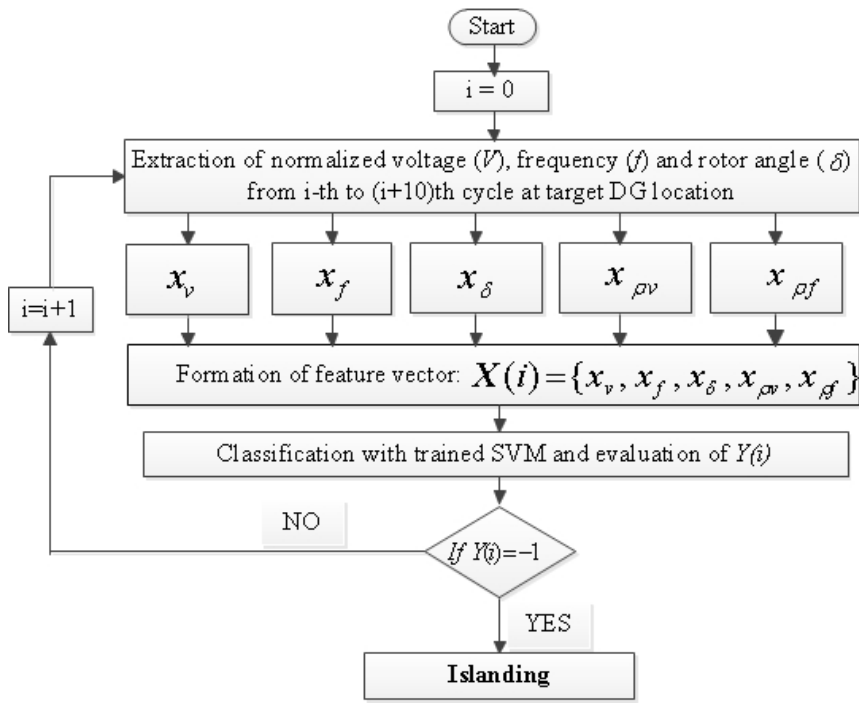

Fig. 3. Flow chart for islanding detection of distributed generation on realtime basis

\section{CASE Study}

\section{A. Test Network}

A test distribution network shown in Fig. 4 has been simulated to extract the necessary features required for classification.
The simulated system is a radial distribution network with base-power of $24 \mathrm{MVA}$. It is comprised of a $132-\mathrm{kV}, 50-\mathrm{Hz}$, subtransmission system with a short-circuit level of 1000 MVA (normal EPS loading), represented by a Thévenin equivalent (marked as Sub in the figure), which feeds a 33$\mathrm{kV}$ distribution system through a $132 / 33-\mathrm{kV}$ transformer. In this system, there are four 6-MVA synchronous generator (SG) connected to bus 5, 7, 9 and 11 respectively and these are connected to the network through 33/0.69 $\mathrm{kV}$ transformer. The lines are modeled as $\pi$ section line. The synchronous generator is represented by a sixth-order threephase model in the $d-q$ rotor reference frame and it is equipped with an AVR represented by the IEEE-Type 1 model, which can be configured to control either terminal voltage or reactive power. In this paper, AVR is operated to control terminal voltage only. The mechanical torque was considered as a constant value throughout the simulation, since the simulation interval is very short (e.g. $1 \mathrm{sec}$ ). Moreover, DGs usually control active power [12], thus it is reasonable to consider constant mechanical torque. Parameters of the synchronous generators, transformers and distribution lines are presented in the Table VI of Appendix.

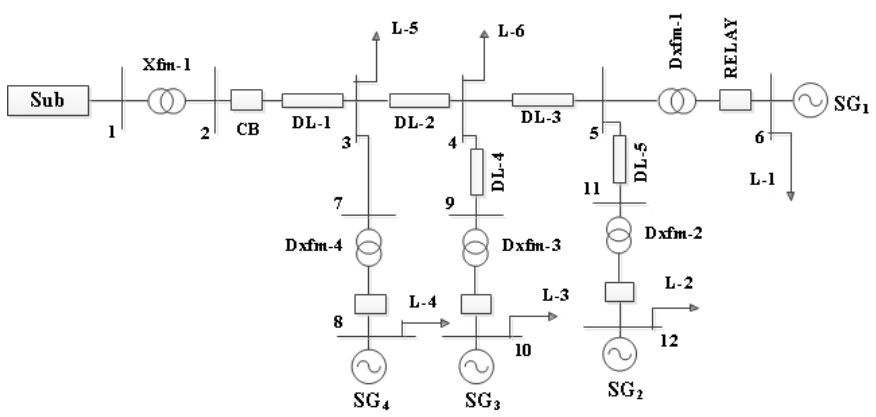

Fig. 4. Single line diagram of a test distribution network under study

The test system is simulated at $2 \mathrm{kHz}$ sampling frequency and the relays are placed at transformer connection points of $\mathrm{SG}_{1}, \mathrm{SG}_{2}, \mathrm{SG}_{3}$ and $\mathrm{SG}_{4}$ respectively, to monitor voltage signal during islanding and non-islanding conditions.

\section{B. Generation of Events}

Islanding can introduce power quality, safety and operational problems [2]. In this study, the network events that results to the isolation of the DG energized distribution network from the supply of the upstream network or grid system are considered as islanding scenarios. Normal events that may exist in practical power systems due to capacitor switching, load switching, etc., for which DG energized network is not isolated, are considered as non-islanding scenarios. Typically, the situations that could be present during islanding and non-islanding conditions are as follows [2], [15]:

- Tripping of main circuit breaker (CB) that could island the distribution network at the presence of 
different range of active power imbalance in the islanded segment.

- Tripping of main circuit breaker (CB) that could island the distribution network at the presence of different range of reactive power imbalance in the islanded segment.

- Switching of load, capacitor bank connected to the distribution network.

- Loss of any branch in the distribution network, apart from distribution line connected to the target DG.

- Balanced three phase fault in a distribution line, apart from distribution line connected to the target DG.

- Tripping of other DGs apart from the target one.

TABLE II

SAMPLE LIST OF THE EVENTS UNDER ISLANDING AND NON-ISLANDING CONDITIONS

\begin{tabular}{|c|c|c|c|}
\hline $\begin{array}{l}\text { Event } \\
\text { name }\end{array}$ & Event description & $\begin{array}{l}\text { Monitoring } \\
\text { end }\end{array}$ & $\begin{array}{l}\text { No. of } \\
\text { Events }\end{array}$ \\
\hline \multirow{4}{*}{ Islanding } & \multirow{4}{*}{$\begin{array}{l}\text { Tripping of CB (at } 0.5 \mathrm{sec}) \text { under } \\
\text { normal }\left(\mathrm{Z}_{\mathrm{S}}=\mathrm{j} 0.024 \mathrm{pu}\right) \text {, a typical } \\
\text { maximum }\left(\mathrm{Z}_{\mathrm{S}}=\mathrm{j} 0.012 \mathrm{pu}\right) \text { and a } \\
\text { typical minimum EPS loading }\left(\mathrm{Z}_{\mathrm{S}}\right. \\
=\mathrm{j} 0.06 \mathrm{pu}) \text { [16]along with the } \\
\text { presence of the followings: } \\
\text { 1) Three types of load: constant } \\
\text { impedance, constant current and } \\
\text { constant power [13]. } \\
\text { 2) Active power imbalance from } \\
0 \% \text { to } 99.9 \% \text { and reactive power } \\
\text { imbalance from } 0 \% \text { to } 50 \% \text { in the } \\
\text { islanded network [13]. }\end{array}$} & DG- $1 / \mathrm{SG}_{1}$ & 366 \\
\hline & & $\mathrm{DG}-2 / \mathrm{SG}_{2}$ & 366 \\
\hline & & $\mathrm{DG}-3 / \mathrm{SG}_{3}$ & 366 \\
\hline & & DG-4/SG 4 & 366 \\
\hline \multirow{4}{*}{$\begin{array}{c}\text { Non- } \\
\text { islanding }\end{array}$} & \multirow{4}{*}{$\begin{array}{l}\text { Under normal }\left(Z_{\mathrm{S}}=j 0.024 \mathrm{pu}\right) \text {, a } \\
\text { typical maximum }\left(\mathrm{Z}_{\mathrm{S}}=\mathrm{j} 0.012 \mathrm{pu}\right) \\
\text { and a typical minimum EPS } \\
\text { loading }\left(\mathrm{Z}_{\mathrm{S}}=\mathrm{j} 0.06 \mathrm{pu}\right) \text { and at the } \\
\text { presence of three types of load } \\
\text { (constant impedance, constant } \\
\text { current and constant power), } \\
\text { several non-islanding events are } \\
\text { generated by considering the } \\
\text { following actions [15]: } \\
\text { 1) Switching of capacitor, } \\
\text { inductive load and non-linear } \\
\text { load at different time within } 10 \\
\text { cycles of observation period. } \\
\text { 2) Balanced three phase fault with } \\
\text { fault clearing time from } 0.05 \mathrm{sec} \\
\text { to } 0.1 \text { sec within the observation } \\
\text { period. } \\
\text { 3) Disconnection of other DGs } \\
\text { apart from the monitoring one. }\end{array}$} & DG- $1 / \mathrm{SG}_{1}$ & 324 \\
\hline & & $\mathrm{DG}-2 / \mathrm{SG}_{2}$ & 324 \\
\hline & & $\mathrm{DG}-3 / \mathrm{SG}_{3}$ & 324 \\
\hline & & DG-4/SG 4 & 324 \\
\hline
\end{tabular}

Several islanding and non-islanding events are generated by conducting repeated simulation on the test network of Fig. 4. Total 1 second time domain simulation is carried out for each events and observation period of 10 cycles (i.e. $0.2 \mathrm{sec}$ duration for fundamental frequency of $50 \mathrm{~Hz}$ ) is considered from $0.5 \mathrm{sec}$ to $0.7 \mathrm{sec}$. A list of generated islanding and nonislanding events are presented in Table II. Variations of active and reactive power are considered to generate a large set of islanding events. As presented in [13], active and/or reactive power imbalance in the islanded segment, acts as a significant factor in the detection of islanding, especially when Vector Surge or Frequency relays are applied. Therefore, in this study, all these scenarios are taken into account while generating the islanding events. The detailed procedure of varying the active and reactive power imbalance is discussed in Appendix.

\section{Analysis of Simulation Results AND PERFormance OF SVM BASED METHOD}

\section{A. Pattern of Features under Islanding and Non-islanding condition}

As presented in section IV-B, a total of 2760 events (including 1464 islanding and 1296 non-islanding) are generated and 5 features for each events are extracted. These features correspond to the events: islanding and nonislanding, and therefore, prior to applying classification task, pattern of features are explored in this sub-section.

In [8], the effectiveness of the conventional Vector Surge (VS) relay, was investigated, and the non detection zone (NDZ) associated with power imbalance factor of the islanded network was discussed. According to [8], for a particular relay setting of $10^{\circ}$ and detection time $(200 \mathrm{~ms})$, a minimum of $43.86 \%$ active power imbalance is needed for a VS relay to detect islanding in the test network energized with Synchronous Generator (Inertia constant $\mathrm{H}=1.5$ ). Hence, in order to highlight the problematic islanding cases of low power imbalance, islanding events with power imbalance of less than $43.86 \%$ are considered as critical islanding cases whereas power imbalance of greater than $43.86 \%$ are considered as non-critical islanding cases. In Fig. 5 , minimum, maximum and mean value of features under critical islanding (total 1020 events), non-critical islanding (total 444 events) and non-islanding cases (total 1296 events) are shown separately.

From Fig. 5 (a), it is observed that considering two features $x_{f}$ and $x_{\delta}$, minimum value of non-critical islanding events is higher than the maximum value of nonislanding events. Therefore, using these two features $x_{f}$ and $x_{\delta}$, non-critical islanding cases can be separated from nonislanding cases quite easily. But, the minimum value of critical islanding features falls inside the range of the value of non-islanding features as shown in Fig. 5 (a), Fig. 5 (b) and Fig. 5 (c). Thus, classification becomes challenging for the critical islanding events and non-islanding events. Hence, it is evident that classification will give poor results if only one or two features are taken into account. Therefore, use of multiple features has been proposed in this paper. 


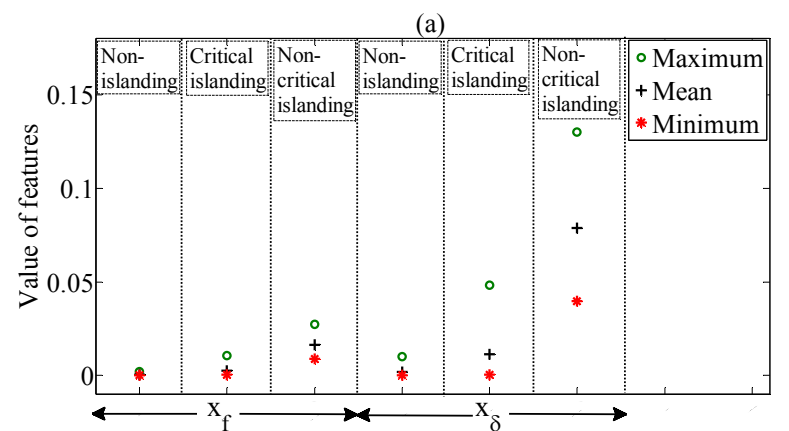

(b)
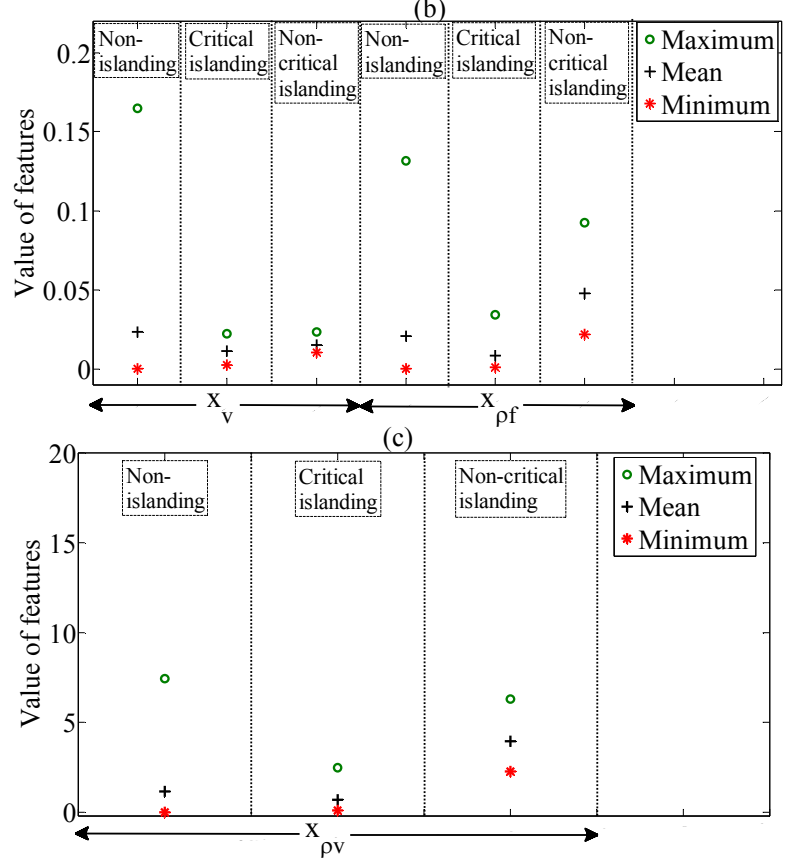

Fig. 5. Variation of features under critical islanding, non-critical islanding and non-islanding cases represented by minimum, maximum and average value of features: (a) $x_{f}$, and $x_{\delta}$ (b) $x_{v}$, and $x_{\rho f}$, (c) $x_{\rho v}$.

\section{B. Classification Results of Multifeature-Based SVM} Method

\section{(1) Overall Performance of Proposed Method:}

According to (21), the feature matrix of 2760 events (including 1464 islanding and 1296 non-islanding) are generated under different operating conditions as presented in section IV. 400 islanding and 400 non-islanding events are used for training purpose and the remaining events are used for testing purpose. 3 -fold cross validation is carried out to determine the values of parameter $\mathrm{C}$ (regularization parameter) and $p$ (polynomial kernel parameter) that results in minimum classification error. Therefore, all data passes through the training and testing stages. Number of SVs (Support Vectors) is also obtained from (14)-(15) incorporating different kernel functions; and with these SVs, an optimal hyperplane is derived. Thus, the trained SVM is achieved and it is tested with the data of 1960 events (including 1064 islanding and 896 non-islanding) to investigate the performance of SVM classifier. The results of classification are presented in Table III.
TABLE III

OVERALl PERFoRMANCE OF SVM BASED ISLANDING DETECTION

\begin{tabular}{|c|c|c|c|c|c|c|}
\hline \multirow[b]{2}{*}{ Kernel } & \multirow{2}{*}{$\begin{array}{c}\text { Parameter } \\
\text { Value }\end{array}$} & \multirow{2}{*}{$\begin{array}{c}\text { No. } \\
\text { of } \\
\text { SVs }\end{array}$} & \multicolumn{2}{|c|}{ No. of events } & \multirow{2}{*}{$\begin{array}{l}\text { DR } \\
(\%)\end{array}$} & \multirow{2}{*}{$\begin{array}{l}\text { FA } \\
(\%)\end{array}$} \\
\hline & & & Islanding & $\begin{array}{c}\text { Non- } \\
\text { islanding }\end{array}$ & & \\
\hline Linear & $C=1000$ & 29 & 1064 & 896 & 99.53 & 0 \\
\hline \multirow{2}{*}{$\begin{array}{c}\text { Polyno } \\
\text { mial }\end{array}$} & $\begin{array}{l}C=1000 \\
\text { and } p=2\end{array}$ & 23 & 1064 & 896 & 99.06 & 0.22 \\
\hline & $\begin{array}{l}C=1000 \\
\text { and } p=3\end{array}$ & 9 & 1064 & 896 & 99.62 & 4.13 \\
\hline
\end{tabular}

Table III shows the results of SVM based classification using linear and polynomial kernels. Linear kernel shows $99.53 \%$ detection rate (DR) with $0 \%$ false alarm (FA), whereas using polynomial kernel (with $p=3$ ), DR of $99.62 \%$ is achieved at the cost of $4.13 \% \mathrm{FA}$.

In this approach, the proposed trained SVM tool is scrutinized with many testing data that can be present during different network conditions including contingencies. In fact, the proposed SVM is trained with less number of training data in comparison to the number of testing data. The proposed approach is assessed under numerous possible testing stages which include critical islanding cases with low power imbalance, and non-islanding cases such as capacitor switching, load switching etc.

\section{(2) Performance under Most Critical Islanding cases:}

To investigate the performance of the proposed method under most critical islanding cases, the features of 756 islanding events with active power imbalance $(\Delta \mathrm{P})$ of $0.5 \%$, $1 \%, 2 \%, 3 \%, 4 \%, 5 \%$ and $6 \%$ are generated separately. Then, for each $\Delta \mathrm{P}$ level, detection rate is obtained using linear kernel SVM. The test results are shown in Fig. 6.

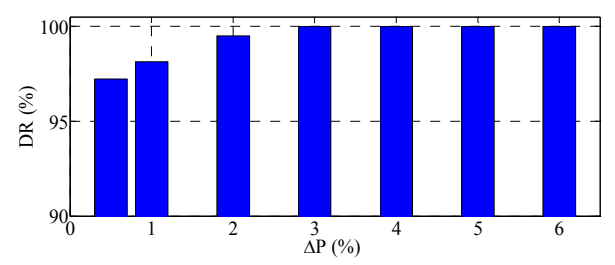

Fig. 6. Detection rate (DR) of SVM (Linear kernel) based islanding detection under most critical islanding cases as a function of $\Delta \mathrm{P}$.

Detection rate (DR) of Fig. 6 is obtained by testing 108 islanding and 896 (see Table III) non-islanding data with trained SVM (linear kernel) at each $\Delta \mathrm{P}$ level. From Fig. 6 and the test results, it is observed that SVM based method can detect most critical islanding cases $(\Delta \mathrm{P} \leq 6 \%)$ with high degree of accuracy and with less than $0.2 \%$ false alarm.

\section{(3) Performance of Proposed Method with Training and} Test data Extracted from different Monitoring Ends:

To investigate the performance of the proposed method under different monitoring ends, SVM is trained with the features obtained from the voltage signal available from one monitoring system (located at a point close to $\mathrm{SG}_{1}$ of Fig. 4) 
and it is tested with the features extracted at other monitoring systems located at other places, such as the locations close to $\mathrm{SG}_{2}, \mathrm{SG}_{3}$ and $\mathrm{SG}_{4}$. Thus, 366 islanding and 324 nonislanding events (see Table II) are used for training purpose and the remaining events are used for test purpose. The test results are presented in Table IV.

TABLE IV

PERFORMANCE OF SVM BASED ISLANDING DETECTION (TRAINING AND TEST AT DIFFERENT MONITORING ENDS)

\begin{tabular}{|c|c|c|c|c|c|c|}
\hline \multirow[b]{2}{*}{ Kernel } & \multirow{2}{*}{$\begin{array}{l}\text { Parameter } \\
\text { Value }\end{array}$} & \multirow{2}{*}{$\begin{array}{l}\text { No. } \\
\text { of } \\
\text { SVs }\end{array}$} & \multicolumn{2}{|c|}{ No. of events } & \multirow{2}{*}{$\begin{array}{l}\text { DR } \\
(\%)\end{array}$} & \multirow{2}{*}{$\begin{array}{l}\text { FA } \\
(\%)\end{array}$} \\
\hline & & & Islanding & $\begin{array}{c}\text { Non- } \\
\text { islanding }\end{array}$ & & \\
\hline Linear & $C=1000$ & 24 & 1098 & 972 & 99.54 & 0 \\
\hline \multirow{2}{*}{$\begin{array}{c}\text { Polyno } \\
\text { mial }\end{array}$} & $\begin{array}{l}C=1000 \\
\text { and } p=2\end{array}$ & 16 & 1098 & 972 & 99.09 & 0.31 \\
\hline & $\begin{array}{l}C=1000 \\
\text { and } p=3\end{array}$ & 7 & 1098 & 972 & 99.64 & 6.69 \\
\hline
\end{tabular}

From the test results of Table IV, it can be concluded that both linear and polynomial kernels show almost similar performance when training and testing are carried out at different monitoring ends. However, from the simulation results, it is revealed that SVM classifier using linear kernel shows $99.54 \%$ detection rate (DR) with $0 \%$ false alarm (FA), whereas polynomial kernel (with $p=2$ ) shows DR of $99.09 \%$ at the cost of $0.31 \%$ false alarm.

\section{(4) Performance of Proposed Method under Trivial Change in Network Topology:}

A slight change in network topology is introduced by eliminating a branch connected through DL-5 as shown in Fig. 4. As a result of this disconnection, the distribution network will now have only three DG units $\left(\mathrm{SG}_{1}, \mathrm{SG}_{3}\right.$ and $\mathrm{SG}_{4}$ ) to feed the local load under islanding condition. Under these circumstances, A total of 720 events (including 360 islanding and 360 non-islanding) are generated under different operating conditions discussed in section IV. SVM is trained with the features obtained at three monitoring stations close to three DG units. The trained SVM is tested with 2760 events (including 1464 islanding and 1296 nonislanding) generated from the test network of Fig. 4. The test results are shown in Table $\mathrm{V}$.

TABLE V

Performance of SVM Based IsLANDing DeteCtion under MinOR CHANGE IN NETWORK TOPOLOGY

\begin{tabular}{|c|c|c|c|c|c|c|}
\hline \multirow[b]{2}{*}{ Kernel } & \multirow{2}{*}{$\begin{array}{l}\text { Parameter } \\
\text { Value }\end{array}$} & \multirow{2}{*}{$\begin{array}{c}\text { No. } \\
\text { of } \\
\text { SVs }\end{array}$} & \multicolumn{2}{|c|}{ No. of events } & \multirow{2}{*}{$\begin{array}{l}\text { DR } \\
(\%)\end{array}$} & \multirow{2}{*}{$\begin{array}{l}\text { FA } \\
(\%)\end{array}$} \\
\hline & & & Islanding & $\begin{array}{c}\text { Non- } \\
\text { islanding }\end{array}$ & & \\
\hline Linear & $C=1000$ & 35 & 1464 & 1296 & 99.79 & 0.15 \\
\hline \multirow{2}{*}{$\begin{array}{c}\text { Polyno } \\
\text { mial }\end{array}$} & $\begin{array}{l}C=1000 \\
\text { and } p=2\end{array}$ & 13 & 1464 & 1296 & 82.1 & 0 \\
\hline & $\begin{array}{l}C=1000 \\
\text { and } p=3\end{array}$ & 7 & 1464 & 1296 & 99.86 & 4.4 \\
\hline
\end{tabular}

Considering the data generated under the above change in network topology, the test results of SVM based method using linear and polynomial kernels are presented in Table $\mathrm{V}$.
For this scenario, higher order polynomial kernel $(p=3)$ shows better performance than lower order polynomial kernel $(p=2)$ in terms of detection rate (DR). However, polynomial kernel of order 3 shows higher false alarm (FA) than lower order $(p=2)$ polynomial kernel. Hence, a trade-off between DR and FA needs to be considered while selecting the order of polynomial kernel. On the other hand, linear kernel shows $99.79 \%$ DR at the cost of only $0.15 \%$ false alarm.

\section{(5) Issues related to Proposed SVM based Method:}

The decision boundary of the proposed SVM based classification technique is established throughout the simulation results of a test network with multiple DGs. The main criteria that define the decision boundary are based on the number of training cases covering as many different nonislanding and islanding events as possible including the different network contingencies and power imbalance levels. Therefore, if significant changes are made in the network or in the circuit topology, decision boundary needs to be reestablished by new simulations and with new training sets.

However, throughout the simulation results, overall performance of the proposed method shows satisfactory results even under most critical islanding cases of low power imbalance. To scrutinize this method, training and testing are carried out at different monitoring end and under minor change of network topology. With properly tuned kernel parameters, test results give detection rate of $98 \%$ and above, with less than $2 \%$ false alarm and thereby show the acceptability of this method. But, to avoid the probable false operation of the proposed method under significant change in network topology, it is suggested to conduct the training of SVM at each monitoring end separately using as many different islanding and non-islanding cases as possible.

\section{CONCLUSION}

This paper has presented the effectiveness of a multiplefeature-based SVM method for islanding detection of distributed generation. 10 cycles of post islanding and nonislanding parameters (voltage, frequency and rotor angle) generated from several credible events are considered to extract five features required to train the SVM. The training of SVM is carried out in off-line and then the trained SVM is applied to detect islanding.

Patterns of features have been analyzed for several nonislanding and islanding cases under different range of power imbalance level and the most critical islanding cases are identified. Overall performance of the proposed method indicates that, with properly tuned kernel parameters, the method can detect islanding with the detection rate of $98 \%$ and above, at the cost of less than $2 \%$ false alarm. Moreover, the decision boundary is also established with Support Vector (SVs) less than $10 \%$ of the training data. Performance of SVM using linear kernel is analyzed for most critical islanding cases which, shows the applicability of the proposed method. The method is further scrutinized by carrying out training and testing on the data extracted at 
different monitoring systems and also with a minor change in network topology. The results indicate that the proposed method can detect islanding with high degree of accuracy under different network contingencies as well as with a minimum power imbalance level.

\section{APPENDIX}

A large number of simulations are carried out to generate several islanding events with different range of active and reactive power imbalance in the islanded network and this is accomplished by changing the load and generation profiles. In this paper, deficits of active and reactive power are taken into account and the process is carried out in the following way.

- Variation of active power imbalance: The deficit of active power imbalance is simulated by keeping the active loads at their nominal values and gradually varying the active power output from 0 to $1 \mathrm{pu}$.

- Variation of reactive power imbalance: The AVR set point is varied from 0.95 to $1 \mathrm{pu}$ and the reactive components of the loads are kept at their rated values. This guarantees that there are cases of deficit of reactive power in the islanded system. For each AVR set point, simulation is also carried out as suggested in [13].

TABLE VI

TEST SYSTEM DATA (FIG. 4)

\begin{tabular}{|c|c|c|c|c|c|}
\hline $\begin{array}{l}\text { Network } \\
\text { Elements }\end{array}$ & $\begin{array}{c}\text { Parameter } \\
\text { s }\end{array}$ & Value & $\begin{array}{l}\text { Network } \\
\text { Elements }\end{array}$ & $\begin{array}{c}\text { Parameter } \\
\text { s }\end{array}$ & Value \\
\hline \multirow{4}{*}{$\begin{array}{l}\text { Thévenin } \\
\text { equivalent } \\
\text { data }(S u b)\end{array}$} & $\mathrm{V}_{\text {base }}(\mathrm{kV})$ & 132 & \multirow{2}{*}{$\begin{array}{c}\text { Loads data } \\
\text { (L-1, L-2, } \\
\text { L-3,L-4) }\end{array}$} & $P_{L}$ & $3 \mathrm{MW}$ \\
\hline & Rated kV & 132 & & $\mathrm{Q}_{\mathrm{L}}$ & $0.5 \mathrm{MVA}$ \\
\hline & SC MVA & 1000 & \multirow{2}{*}{$\begin{array}{c}\text { Loads data } \\
\text { (L-5, L-6) }\end{array}$} & $\mathrm{P}_{\mathrm{L}}$ & $6 \mathrm{MW}$ \\
\hline & Frequency & $50 \mathrm{~Hz}$ & & $\mathrm{Q}_{\mathrm{L}}$ & $1.4 \mathrm{MVA}$ \\
\hline \multirow{5}{*}{$\begin{array}{c}\text { Transform } \\
\text { ers data } \\
(X f m-1)\end{array}$} & Rated kV & $\begin{array}{l}132 / 33 \\
(\Delta / \mathrm{Yg})\end{array}$ & \multirow{5}{*}{$\begin{array}{c}\text { Transform } \\
\text { ers data } \\
(D \times f m-1, \\
D \times f m-2, \\
D \times f m-3, \\
D \times f m-4)\end{array}$} & Rated kV & $\begin{array}{c}33 / 0.69 \\
(\Delta / Y g)\end{array}$ \\
\hline & $\begin{array}{l}\text { Rated } \\
\text { MVA }\end{array}$ & 100 & & $\begin{array}{l}\text { Rated } \\
\text { MVA }\end{array}$ & 30 \\
\hline & Frequency & $50 \mathrm{~Hz}$ & & Frequency & $50 \mathrm{~Hz}$ \\
\hline & $\begin{array}{c}\text { Resistance } \\
(\mathrm{pu})\end{array}$ & 0.00375 & & $\begin{array}{c}\text { Resistance } \\
\text { (pu) }\end{array}$ & 0.00375 \\
\hline & $\begin{array}{c}\text { Inductanc } \\
\mathrm{e}\end{array}$ & $0.1 \mathrm{pu}$ & & Inductance & $0.1 \mathrm{pu}$ \\
\hline \multirow{3}{*}{$\begin{array}{c}\text { Lines data } \\
(D L-1 \text {, } \\
D L-2, D L- \\
3, D L-4 \\
D L-5)\end{array}$} & Resistance & $0.4 \Omega / \mathrm{km}$ & \multirow{14}{*}{$\begin{array}{c}\text { Synchrono } \\
\text { us } \\
\text { generator } \\
\text { data } \\
\left(S G_{1}, S G_{2} \text {, }\right. \\
S G_{3} \text {, and } \\
\left.S G_{4}\right)\end{array}$} & Frequency & $50 \mathrm{~Hz}$ \\
\hline & $\begin{array}{l}\text { Inductive } \\
\text { reactance }\end{array}$ & $1.6 \Omega / \mathrm{km}$ & & $\begin{array}{l}\mathrm{V}_{\text {base }}(\mathrm{kV}) / \\
\text { Rated kV }\end{array}$ & 0.69 \\
\hline & $\begin{array}{c}\text { Line } \\
\text { Length }\end{array}$ & $10 \mathrm{~km}$ & & $\begin{array}{l}\text { Rated } \\
\text { MVA }\end{array}$ & 6 \\
\hline \multirow{11}{*}{$\begin{array}{c}\text { Exciter } \\
\text { of } S G_{1} \text {, } \\
S G_{2}, S G_{3} \text {, } \\
\text { and } S G_{4}\end{array}$} & $\operatorname{Tr}(\mathrm{s})$ & 0.005 & & Pole pairs & 2 \\
\hline & $\mathrm{Ka}$ & 200 & & $\mathrm{H}(\mathrm{s})$ & 1.5 \\
\hline & $\mathrm{Ta}(\mathrm{s})$ & 0.001 & & $\mathrm{X}_{\mathrm{d}}(\mathrm{pu})$ & 1.4 \\
\hline & $\mathrm{Ke}$ & 1 & & $\mathrm{X}_{\mathrm{d}}^{\prime}(\mathrm{pu})$ & 0.23 \\
\hline & $\mathrm{Te}(\mathrm{s})$ & 0 & & $\mathrm{X}_{\mathrm{d}}{ }^{\prime \prime} / \mathrm{X}_{\mathrm{q}}{ }^{\prime \prime}$ & 0.12 \\
\hline & \multirow{2}{*}{$\mathrm{Kf}$} & \multirow{2}{*}{0.001} & & $\mathrm{~T}_{\mathrm{d} 0}(\mathrm{~s})$ & 5.5 \\
\hline & & & & $\mathrm{T}_{\mathrm{d} 0}{ }^{\prime \prime}(\mathrm{s})$ & 0.05 \\
\hline & \multirow{2}{*}{$\operatorname{Tf}(\mathrm{s})$} & \multirow{2}{*}{0.1} & & $\mathrm{~T}_{\mathrm{q} 0}{ }^{\prime}(\mathrm{s})$ & 1.25 \\
\hline & & & & $\mathrm{T}_{\mathrm{q} 0}(\mathrm{~s})$ & 0.19 \\
\hline & $\begin{array}{c}\mathrm{V}_{\text {RMAX }} \\
(\mathrm{pu})\end{array}$ & 7 & & $\begin{array}{c}\text { Stator } \\
\text { resistance }\end{array}$ & $0.0014 \mathrm{pu}$ \\
\hline & $\mathrm{V}_{\mathrm{RMIN}}(\mathrm{pu})$ & 0 & & $\begin{array}{c}\text { Leakage } \\
\text { reactance }\end{array}$ & $0.05 \mathrm{pu}$ \\
\hline
\end{tabular}

\section{REFERENCES}

[1] Xuancai Zhu, Chengrui Du, Guoqiao Shen, Min Chen, and Dehong Xu, "Analysis of the non-detection none with passive islanding detection methods for current control DG system," in Proc. 24 $4^{\text {th }}$ Annual IEEE Applied Power Electronics Conference and Exposition (APEC), Washington DC, USA, pp. 358-363, 15-19 February 2009.

[2] K. El-Arroudi, and G. Joos, "Data mining approach to threshold settings of islanding relays in distributed generation," IEEE Trans. Power Systems, vol. 22, no. 3, pp. 1112-1119, August 2007.

[3] Waleed K. A. Najy, H. H. Zeineldin, Ali H. Kasem Alaboudy, and Wei Lee Woon, "A Bayesian passive islanding detection method for inverter-based distributed generation using ESPRIT," IEEE Trans. Power Delivery, vol. 26, no. 4, pp. 2687-2696, October 2011.

[4] H. Bitaraf, M. Sheikholeslamzadeh, A. M. Ranjbar, and B. Mozafari, "Neuro-fuzzy islanding detection in distributed generation," in Proc. IEEE Conference on Innovative Smart Grid Technologies - Asia (ISGT Asia), Tianjin, pp. 1-5, 21-24 May 2012.

[5] S. R. Samantaray, K. El-Arroudi, G. Joos, and I. Kamwa, "A fuzzy rule-based approach for islanding detection in distributed generation," IEEE Trans. Power Delivery, vol. 25, no. 3, pp. 1427-1433, July 2010.

[6] N. Senroy, G. T. Heydt, and V. Vittal, "Decision Tree assisted controlled islanding," IEEE Trans. Power Systems, vol. 21, no. 4, pp. 1790-1797, December 2006.

[7] C. T. Hsieh, J. M. Lin, and S. J. Huang, "Enhancement of islandingdetection of distributed generation systems via wavelet transform based approaches," International Journal of Electrical Power \& Energy Systems, vol. 30, No. 10, pp. 575-580, December 2008.

[8] W. Freitas, Zhenyu Huang, and Wilsun Xu, "A practical method for assessing the effectiveness of vector surge relays for distributed generation applications," IEEE Trans. Power Delivery, vol. 20, no. 1, pp. 57-63, January 2005.

[9] Jose C. M. Vieira, Walmir Freitas, and D. Salles, "Characteristics of voltage relays for embedded synchronous generators protection," IET journals on Generation, Transmission \& Distribution, vol. 1, no. 3, pp. 484-491, May 2007.

[10] V. N. Vapnik, Statistical Learning Theory. New York: Wiley, 1998.

[11] N. Cristianini and J. Shawe-Taylor, An Introduction to Support Vector Machines and Other Kernel-based Learning Methods, Cambridge, MA: Cambridge Univ. Press, 2000.

[12] N. Jenkins, R. Allan, P. Crossley, D. Kirschen, and G. Strbac, Embedded Generation, 1st ed. Bristol, U.K.: Inst. Elect. Eng., 2000.

[13] Jose C. M. Vieira, Walmir Freitas, Wilsun Xu, and Andre Morelato, "An investigation on the nondetection zones of synchronous distributed generation anti-islanding protection," IEEE Trans. Power Delivery, vol. 23, no. 2, pp. 593-600, April 2008.

[14] M. R. Alam, K. M. Muttaqi, and A. Bouzerdoum, "A short length window-based method for islanding detection in distributed generation," in Proc. International Joint Conference on Neural Networks (IJCNN), Brisbane, Qld, pp. 1-6, 10-15 June 2012.

[15] S. R. Samantaray, B. Chitti Babu, and P. K. Dash, "Probabilistic neural network based islanding detection in distributed generation," Electric Power Components and Systems, vol. 39, no. 3, pp. 191-203, Feb. 2011.

[16] K. El-Arroudi, G. Joos, I. Kamwa, and D. T. McGillis, "Intelligentbased approach to islanding detection in distributed generation," IEEE Trans. Power Del., vol. 22, no. 2, pp. 828-835, Apr. 2007.

[17] Rajesh Ku. Tripathy, Ashutosh Acharya, and Sumit Kumar Choudhary, "Gender classification from ECG signal analysis using least square support vector machine," American Journal of Signal Processing, vol. 2, no. 5, pp. 145-149, 2012.

\section{BIOGRAPHIES}

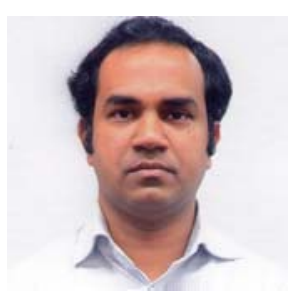

Mollah Rezaul Alam (Std. Member'12) received the B.Sc. degree in Electrical and Electronic Engineering from Bangladesh University of Engineering \& Technology (BUET), Dhaka, Bangladesh in 2005. Currently, he is pursuing the Ph.D. degree at the University of Wollongong, New South Wales, Australia. 
Prior to starting Ph.D. studies, he was involved in the telecommunication industry in Bangladesh for 5 years, where he worked in the area of Intelligent Network \& Value Added Services of cellular mobile technology. His research interests include computational intelligence, data mining, fault detection, classification and analysis considering the impacts of distributed energy resources.

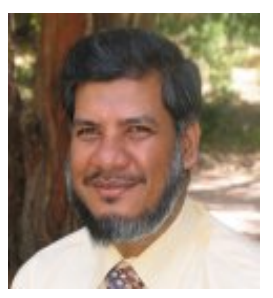

Kashem M. Muttaqi (M'01, SM'05) received the B.Sc. degree in electrical and electronic engineering from Bangladesh University of Engineering and Technology (BUET), Bangladesh in 1993, the M.Eng.Sc. degree in electrical engineering from University of Malaya, Malaysia in 1996 and the $\mathrm{Ph} . \mathrm{D}$. degree in Electrical Engineering from Multimedia University, Malaysia in 2001. Currently, he is an Associate Professor at the School of Electrical, Computer, and Telecommunications Engineering, and member of Australian Power Quality and Reliability (APQRC) at the University of Wollongong, Australia. He was associated with the University of Tasmania, Australia as a Research Fellow/Lecturer/Senior Lecturer from 2002 to 2007, and with the Queensland University of Technology, Australia as a Research Fellow from 2000 to 2002. Previously, he also worked for Multimedia University as a Lecturer for three years. He has more than 17 years of academic experience and has authored or coauthored over 165 papers in international journals and conference proceedings. His research interests include distributed generation, renewable energy, electrical vehicles, smart-grid, power system planning and control. Dr. Muttaqi is an Associate Editor of the IEEE TRANSACTIONS ON INDUSTRY APPLICATIONS.

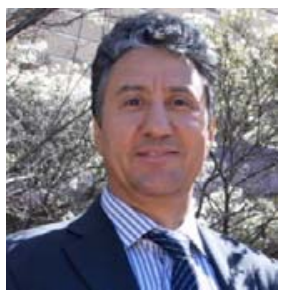

Abdesselam Bouzerdoum (M'89-SM'03) received the M.Sc. and Ph.D. degrees in electrical engineering from the University of Washington, Seattle, WA, USA.

In 1991, he joined The University of Adelaide, Adelaide, Australia, and in 1998, he was appointed an Associate Professor with Edith Cowan University, Perth, Australia. Since 2004, he has been with the University of Wollongong, Wollongong, Australia, as Professor of Computer Engineering, where he also served as Head of School of Electrical, Computer and Telecommunications Engineering from 2004 to 2006 and Associate Dean (Research), with the Faculty of Informatics, from 2007 to 2013. From 2009 to 2011, he served as a Member of the Australian Research Council College of Experts, and was the Deputy Chair of the Engineering, Mathematics and Informatics panel from 2010 to 2011.

Dr. Bouzerdoum was the recipient of numerous awards and prizes; the most notable are the Eureka Prize for Outstanding Science in Support of Defence or National Security in 2011, the Chester Sall Award in 2005, and a Distinguished Researcher Award (Chercheur de Haut Niveau) from the French Ministry of Research in 2001. He has published over 280 technical articles and graduated many Ph.D. and Masters students. From 1999 to 2006, he served as an Associate Editor of IEEE TRANSACTIONS ON SYSTEMS, MAN, AND CYBERNETICS. 